EDITOR

Roger Jones, DM, FRCP, FRCGP, FMedSci London

DEPUTY EDITOR

Alec Logan, FRCGP

Motherwell

JOURNAL MANAGER

Catharine Hull

SENIOR ASSISTANT EDITOR

Erika Niesner

ASSISTANT EDITOR

Moira Davies-Cinar

EDITORIAL ASSISTANT

Tania Marszalek

ADVERTISING EXECUTIVE

Brenda Laurent

EDITORIAL BOARD

Richard Baker, MD, FRCGP

Leicester

Stephen Barclay, MD, FRCGP, DRCOG

Cambridge

Jenny Blythe, MRCGP, DRCOG, DCH

London

Chris Butler, MD, MRCGP

Cardiff

Kath Checkland, PhD, MRCGP

Manchester

Graham Easton, MSc, MRCGP

London

Mark Gabbay, MD, FRCGP

Liverpool

Murray Lough, MD, FRCGP

Glasgow

Nigel Mathers, MD, FRCGP, DCH

Sheffield

Tim Peters, MSc, PhD, CStat, FFPH

Bristol

Bruno Rushforth, MRCGP, DFSRH, DRCOG

Leeds

Chris Salisbury, MD, FRCGP

Bristol

John Sandars, MSc, MD, FRCGP, MRCP

Leeds

Mark Shapley, FRCGP, DCH, DRCOG

Newcastle-under-Lyme

Niroshan Siriwardena, MMedSci, PhD, FRCGP Lincoln

2009 impact factor: 2.442

EDITORIAL OFFICE

1 Bow Churchyard, London, EC4M 9DQ

(Tel: 0203188 7400, Fax: 0203188 7401).

E-mail: journal@rcgp.org.uk

http://www.rcgp.org.uk/bjgp.aspx

PUBLISHED BY

The Royal College of General Practitioners,

1 Bow Churchyard, London, EC4M 9DQ.

Registered charity number 223106. The BJGP is

published by the RCGP, but has complete

editorial independence. Opinions expressed in the

BJGP should not be taken to represent the policy

of the RCGP unless this is specifically stated.

No endorsement of any advertisement is implied or intended by the RCGP.

PRINTED IN GREAT BRITAIN BY

HPM Limited, Prime House, Park 2000, Heighington

Lane Business Park

Newton Aycliffe, Co. Durham DL5 6AR.

Printed on $100 \%$ recycled paper

ISSN 0960-1643 (Print)

ISSN 1478-5242 (Online)

\title{
April Focus
}

\section{TALKING HELPS - OR DOES IT?}

Qualitative methodologies have an established place in primary care research. Not only do qualitative studies frequently complement quantitative work, such as helping to understand why a particular intervention worked or didn't work, alongside quantitative measurement of its effect size, they are also capable of illuminating key behavioural aspects of practice, such as the uptake or otherwise of guidelines or the decision to prescribe or not prescribe an antibiotic. Many qualitative studies go well beyond hypothesis generation and add substantially to the evidence base, especially in the fields of translational research and the implementation of innovations.

A range of approaches taken and topics studied by qualitative methods is found in this month's Journal. Some worrying findings emerged from Edge's study of black Caribbean women who took part in focus groups to discuss perinatal mental health care and related topics (page 256). Many of them reported unsatisfactory doctor-patient relationships which deterred them from being open about their problems and from seeking care. Concrete suggestions for improving this situation also came out of this work, and their implementation could be the subject of future research in this important field. Two other studies focused on depressed people. Searle and co-workers elicited their views about 'facilitated physical activity' (page 254) as a treatment in lengthy one-toone interviews and reported fairly positive views of its acceptability and efficacy, somewhat related to the explanatory models of depression held by the patients. Medication was seen as preferable by those less motivated to exercise. Schofield and colleagues explored the concept of expertise among patients on long-term antidepressant medication in semistructured interviews and describe a 'journey' from novice to expert, often by trial and error, which can culminate in a patient developing control over the medication and the illness, while also requiring the patient's doctor to be aware of the changes taking place in the therapeutic relationship (page 252)

Practice staff were the research participants in Campbell and colleagues' interview study on exception reporting (page 276) - identifying and excluding from the performance target denominator certain patients, such as those who are noncompliant with therapy or refuse investigations (non-discretionary exceptions) and others, such as those with terminal illness, comorbidity which negates an indication for therapy for another condition, or are intolerant of medications (discretionary exceptions). Practice staff took this process very seriously and regarded exception reporting as a relatively rare event which can contribute to wholeperson and patient-centred care.

Some important implications for the use of patient and peer feedback as part of plans for revalidation emerged from Edwards' and co-authors' paper on GPs' views of patient experience surveys, gathered in semi-structured interviews (page 263). Although GPs recognise the importance of getting feedback from patients, they generally thought that, at least as presently constructed, patientexperience surveys lacked a clear purpose and often were difficult to interpret in terms of training or changing behaviour.

In a rather disquieting report from the Netherlands, Slort and colleagues provide information on the views of GPs, consultants, and patients about each other's roles in palliative care, using small facilitated focus groups (page 265). Somewhat disparaging comments were made by specialists about GPs, while the GPs gave their views on the way they contributed to palliative care by being accessible, considerate, and respectful and by providing continuity. It might be that some of the GP-specialist mismatch derived from the questions asked in the focus groups.

Focus groups were also used by Adams and colleagues in their important study of the way that cancer reviews are working in primary care (page 274). As the numbers of cancer survivors inexorably rises and their care shifts to the community, the role of primary care will become increasingly important. This paper suggests that we have some way to go, both within general practice and in our communication with secondary care - and this is probably a message that can be generalised to include the care of chronic diseases of all kinds outside the hospital.

\section{Roger Jones}

Editor

DOI: 10.3399/bjgp11X566983

(c) British Journal of General Practice 2011; 61: 241-312. 